\title{
Projector Tracking System using RFID
}

\author{
Fairuz Rauf \\ Faculty of Communication, \\ Visual Art and Computing \\ Universiti Selangor \\ Malaysia
}

\author{
Prithvaraju Mahaletchnan \\ Faculty of Communication, \\ Visual Art and Computing \\ Universiti Selangor \\ Malaysia
}

\author{
Zuraidy Adnan \\ Faculty of Communication, \\ Visual Art and Computing \\ Universiti Selangor \\ Malaysia
}

\begin{abstract}
This system is developed for Faculty of Communication, Visual Art and Computing. FCVAC, Universiti Selangor (UNISEL). The purpose of this system is to track the projector real time location. This system also will help to increase the effectiveness of tracking process. Other than that, this system is develop for track projector current location in a short period by using RFID technology which stand for Radio Frequency Identification. RFID enables radio detection and recognition of an objects associated with a unique ID number code carried by the RFID tag. This system is used by FCVAC Admin. Admin staff can add projector, remove projector and track last location of projector. All the tracking details will be recorded in log. Admin staff can view the $\log$.
\end{abstract}

\section{Keywords}

RFID, framework

\section{INTRODUCTION}

Projector is an output device which can transfer images from computer or Blu-ray player and reimage them onto a wall, screen or other flat surface. The first carousel slide projector was patented on May 11, 1965 by a man named David Hansen. The digital projector we know today was created by Gene Dolgoff in 1984, although he came up with the concept for it in 1968. There are various uses of projector such as for education as a learning tool, business and etc.

FCVAC is stand for Faculty of Communication, Visual Art and Computing. FCVAC is computing and full of IT uses. In FCVAC the main teaching tool for student which is use by every lecturer is projector. Every time before lecturer enter the class lecturer need to borrow the projector from Admin office. These are some steps should follow by the lecturer to borrow the projector, first lecturer need to check whether there any projector is available, then if the projector available lecturer need to fill the logbook then they can use it. If there is no projector available lecturer need to inform the Admin staff. The admin staff will check the logbook and contact the last lecturer who use the projector. Sometime lecturer who is rushing for class will not fill the log book and just take away the projector. Due to that, the admin staff will contact every lecturer or email them to return back the projector.

The project that will be developed is known as Projector Tracking System Using Radio Frequency Identification (RFID) for FCVAC Admin office. The idea of the project is each projector will be attached a RFID tag and each classrooms and labs will be installed with RFID tag reader. Radio-Frequency Identification (RFID) is the use of radio waves to read and capture information stored on a tag attached to an object. A tag can be read from up to several feet away and does not need to be within direct line-of-sight of the reader to be tracked. RFID enables radio detection and recognition of an objects associated with a unique ID number code carried by the RFID tag. (Peter Solic, 2013)

\subsection{Background of Study}

In Universiti Selangor (UNISEL) previously known as University Industri Selangor was established on 23rd August 1999. UNISEL currently operating two campuses, Bestari Jaya and Shah Alam. Bestari Jaya Campus is located at Jalan Timur Tambahan, 45600 Bestari Jaya, Selangor. At UNISEL Bestari Jaya there are three faculty, which is Faculty of Communication, Visual Art and Computing, Faculty of Engineering and Life Sciences, Faculty of Education and Social Science.

FCVAC is stand for Faculty of Communication, Visual Art and Computing. Currently do not have any system for tracking projector. Lecturer need to borrow the projector manually where lecturer need to fill the logbook at admin office to start the class. If any unreturnable projector found by admin staff, they will mail the particular lecturer. If the admin staff found that any projector haven't been return in specific time, they will immediately mail to the lecturer who borrowed the projector from the office.

\subsection{Problem Statement}

1) The potential of projector status not been recorded by admin staff is high.

- The staff may forget or refuse to write the projector borrowing record in log book.

2) Difficult to know the current location of the projector.

- Admin staff will difficult to know the current location of the projector if any data lost that written logbook by lecturer.

3) Limited projector tracking system in FCVAC.

- Currently FCVAC using manually where the admin staff will email every lecturer to inform them for return back the projector.

\subsection{Objective}

1) To propose the system to avoid missing or loss of projector records.

- $\quad$ By having RFID technology, the Admin staff can view the records and status of the projector.

2) To develop a tracking system to trace projector current location, date and time.

- By having RFID tag on the projector and RFID detector in classroom, the current location will be traced.

3) To develop Projector Tracking System using RFID for Computing Department.

- This will let admin staff to know the current location of the projector with by using this system. 


\subsection{Scope of Study}

This project will consist three lecturers, three classroom (BK) and three projectors. The listing below will explain the technology used and user.

\section{- Technology}

RF referring to radio frequency, which is any frequency within the electromagnetic spectrum associated with radio wave propagation. When an RF current is supplied to an antenna, an electromagnetic area is created that then is able to broadcast through space. Many wireless technologies are based on RF area propagation.

\section{- User}

This project is developed for computing department admin to track the projectors real time location.

\subsection{Significance of Project}

Projector Tracking System using RFID system for FCVAC will be helpful for Admin management since the system will be able to keep track the projector current location, date and time. Moreover, the data is recorded automatically in database whenever the projector is taken from the Admin Office and the current location will be recorded. Therefore, there are no more any manual system to borrow the projector, which is lecturer need to check whether there any projector is available, then if the projector available lecturer need to fill the logbook. If there is no projector available lecturer need to inform the Admin staff. The admin staff will check the logbook and contact the last lecturer who use the projector. The admin staff will check the logbook and contact the last lecturer who use the projector or email every lecturer.

\subsection{Constraint \& Critical Assumption}

1. Internet connections

- Since the system run on web based platform, the Admin must have an internet connection in order to use the services. Admin able access the system at anytime and anywhere without any interrupting unless the Internet connection disturbance to know the current location of the projector.

2. Technology constrains

- Since the projector tracking system using RFID, the projector tag must be certain range to be detected. The RFID tag only will detect by the RFID reader in certain range, whenever the projector is taken from Admin office the projector must be in certain range to be detected by the RFID reader to know the real-time location of projector.

\section{LITERATURE REVIEW \\ 2.1 Introduction}

This chapter review the basic purposes of current knowledge including substantive discoveries and also hypothetical and methodological commitments to a specific subject. In this topic, this literature review will discuss about the tracking. This literature review is a summary and explanation of the complete and current state of knowledge on limited topics as found in academic books and journal articles.

Other than that, this chapter also review of journal and articles which related to the main topic of project and also comparison of the project system with the already exist RFID tracking system been studied. The existing system that have been studied are BizLogics (Employee Tracking System), GAO RFID (Asset Tracking System) and SysAid.

\subsection{Technology in Use-RFID}

There are many technologies used to develop the proposed system. Studies had been done on the available hardware and software that can be used in the system.

\subsubsection{Hardware}

\subsubsection{RFID Technology}

RFID stands for Radio-Frequency Identification. RFID is a small electronic device that consist of a small chip and an antenna. The chip is capable of carrying 2,000 bytes of data or less. RFID device can serve the same purpose as a bar code or a magnetic strip on the back of a credit card or ATM card it provides a unique identifier for that object. And, just as a bar code or magnetic strip must be scanned to get the information, the RFID device must be scanned to retrieve the identifying information. An RFID system largely consists of tags as transponder, reader and antenna as transceiver.

\subsubsection{RFID Tag}

An RFID tag is an ID system which uses in Radio Frequency Identification (RFID) devices. The RFID tag that contain without a power source are known as passive tags and those their own power source is known as active tags.

Passive RFID tags is an easy tag that can read by powered reader. Passive RFID are commonly used as identifier for assets ranging from assets in warehouse since passive tags only can hold a few kilobytes of information. Passive tags cannot perform any calculation, it can only be read. Some passive tags cannot be rewritten only hold a unique identifier and cannot be changed, while another passive tag can be rewritten while being reading. Other than that, passive tags can get at low price and it can be printed for only a few cents per tag. Since passive tags is unpowered so its lifetime normally unlimited.

Active RFID tags generally have longer wave length which can enabling it to work a little better. Active RFID have been quietly saving millions of dollars for enterprises all over the world. Active tags have an internal power source and use the energy supplied for both, to power the microchip and to generate a signal on the antenna. (Christoph 2013). This extends the range of the tags and has capable to communicating advance information such as location. Active RFID tags have tree main part which is interrogator, antenna and a tag. Active tags which is powered by a battery will last between three to five years, but if the battery fails the active RFID tag need to be replace. Active tags can be divided in two types which is Transponder and Beacons. Transponder is a very efficient because it conserves battery life when the tag is out of range of the reader. The reader will send the signal first and then the active transponder will send a signal back with the relevant. Meanwhile Beacons can be read hundred meters range.

\subsubsection{RFID Reader}

RFID reader is a device used to communicate with RFID tags. RFID tag also called as interrogator because it will interrogator the RFID tags. The reader has one or more antennas, which can emit radio waves and receive signal back, from the RFID tag. (Jayalakshmi J, 2016). The RFID reader will connect with the tag and the host computer. The reader will receive information from tag and send it into the host computer by standard interface. 


\section{RESEARCH METHODOLOGY}

\subsection{Introduction}

The methodology chosen must be appropriate and suitable for the development of the system as it will be step by step guide that the developer must follow in order to deliver the system successfully (Kim, 2011). In this chapter the software development methodology was clearly discuss on Prototyping model. This Prototyping model methodology was a tool that uses to develop a proposed system. The data collecting method applied and conducted some interviews to know user requirements. The user requirement deeply analyses based on the Prototyping model methodology phases.

\subsection{Data Collection Method}

\subsubsection{Interview}

Interview is a conversation or communication that happen between one or more than one person. There are several ways to conduct the interview, there are face-to-face interaction, conducted in surveys, through the Internet to more informal conversations conducted for research purposes. This system which is Projector Tracking System Using Radio Frequency Identification (RFID) For Computing Department was used face to face interview to gather information. The interview session mainly involved two users which is FCVAC Admin staff and FCVAC lecturers. The purpose of conducting the interview is to collect user requirements are the essential in developing this project. The information gathered from the interview is to come out for user requirement both functional and non-functional requirements.

\subsection{Data Analysis Methods}

All the requirement data that has been collect from interview (refer appendix B) will be analyses one by one to get the proper solution for the problem and design the solution they need. The interviews question and solution will be analyzed systematically through interactive and repeat reading it. Through this, the developer will able to know the user requirement and develop the system as the user requirement

\subsection{Software Development Methods}

For "Projector Tracking System Using Radio Frequency Identification (RFID) For Computing Department" project will be using Prototype Model Methodology as development. There are various iterations of requirements uses for Prototype model such as Planning, Analysis, Design, Implementation (Prototype), Implementation (Final system). This method is chosen because it has the ability to address risk early in this project, early feedback on whether the final system will be acceptance and visible progress throughout the project. The advantages and disadvantages of this method are shown in Table 1 below.
Table 1: Advantages and Disadvantages of Prototyping Model

\begin{tabular}{|l|l|}
\hline Advantages & Disadvantages \\
\hline $\begin{array}{l}\text { Decrease development time } \\
\text { as an initial versionof } \\
\text { system(prototype) is } \\
\text { developed in early stage. }\end{array}$ & $\begin{array}{l}\text { Waste of time and waste of } \\
\text { money, the prototype need to } \\
\text { rebuild if the user not } \\
\text { accepted. }\end{array}$ \\
\hline $\begin{array}{l}\text { Due to the good functioning } \\
\text { of final system user have } \\
\text { better understanding about } \\
\text { the system. }\end{array}$ & $\begin{array}{l}\text { The dificult of the final } \\
\text { system increase when the } \\
\text { scope of orginal plan of } \\
\text { system is expand. }\end{array}$ \\
\hline $\begin{array}{l}\text { Systems error will be } \\
\text { dectacted buring early stages } \\
\text { and can reduce risk. }\end{array}$ & $\begin{array}{l}\text { the prototype is not able to } \\
\text { reuse because of bab quality } \\
\text { of code developed. }\end{array}$ \\
\hline $\begin{array}{l}\text { Strong comunication between } \\
\text { users and developers }\end{array}$ & $\begin{array}{l}\text { Contract may be awarded } \\
\text { without rigorous evaluation of } \\
\text { Prototype }\end{array}$ \\
\hline $\begin{array}{l}\text { Missing functionality can be } \\
\text { identified easily }\end{array}$ & $\begin{array}{l}\text { Identifying non-functional } \\
\text { elements difficult to } \\
\text { document }\end{array}$ \\
\hline
\end{tabular}

Prototyping model is a good option compare other methodologies like spiral model, waterfall model which require more technical knowledge and time to conduct or maintain low error which may occur in every stage. By using this Prototype Model will help the user to get better understanding about the system at early stages. Hence, this model has high user involvement. Other than that, by using this model error will be detected on the early stage. Thus, this will help the developer to reduce risk of failure of the system. As conclusion Prototype Model is a good and suitable to be used to develop this project.

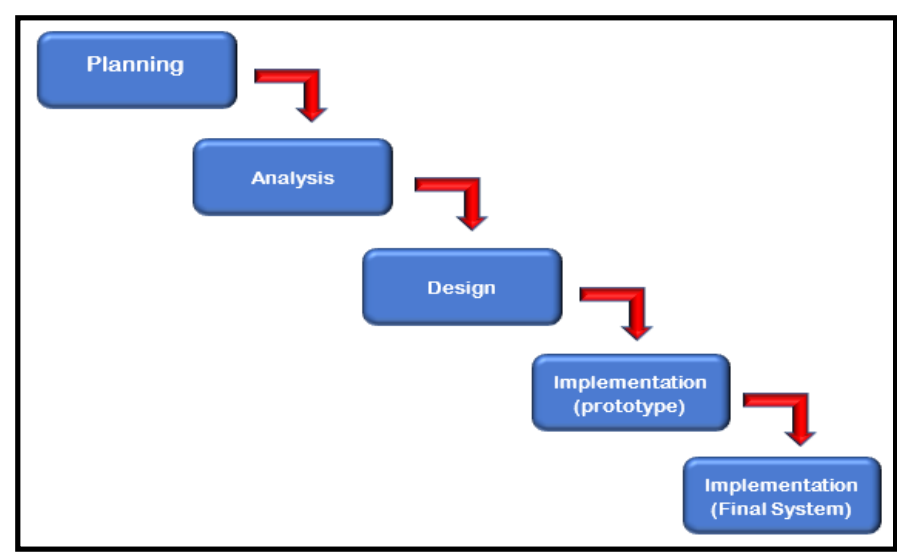

Figure 1: Prototype Model

\subsubsection{Planning}

Planning has been done in the early stage. A discussion has been done with project supervisor and come out with suitable title which is "Projector Tracking System Using Radio Frequency Identification (RFID) For Computing Department”. Unfortunately, in Universiti Selangor there is no any system done before to track projector. Thus, this will be difficult for the developer to develop the project without any reference. In FCVAC the common problem face by the Amin Staff is to detect the real-time location of the projector. The objective of the project is to develop a system a system which can help the Admin staff to detect the real-time location of the projector. Based on the problem statements objective of proposed system 
had been clarified. It is to develop a projector tracking system and to safe time for Admin staff.

\subsubsection{Analysis}

In this stage, analysis have been done base on interview (refer appendix B). Admin staff want to know where the location of the projector instead of call of email is every lecturer in FCVAC. A research on technology needed is to know how the technology work and make use of it in proposed system. Finally, study on suitable methodology is to understand more about the chosen methodology in aiding the proposed system development process.

\subsubsection{Design}

In this stage, the development of the proposed system is started and the functional system has to be developed at this stage. The development of the proposed system is begun and the functional system has to be developed at this stage. The next step would be the design of database; the Entity Relationship Diagram (ERD) must be designed so that the entities can be extracted. All the data needed for the system must be included and properly assigned. Primary key and the foreign key of each table should be assigned in order to draft out the relationship for every table in the database.

\subsubsection{Implementation (Prototype)}

In this stage the prototype is developed and implemented in real environment. Admin staff will test on the prototype and evaluate the system. First Admin staff will be testing the first prototype based on plan on stage 3. Evaluation for the first prototype will be performed based tested result gather from the Admin staff. This testing is performed to verify the acceptance of the prototype by Admin staff. Observation is performed while the prototype is implemented in real environment to check whether the feature and function provided in the prototype is satisfied the user requirement discussed in the early stage. If the user is not satisfied with the current prototype functionalities, interview will be done with the Admin staff to acquirements. Thus new prototype will be developed based on new requirements.

\subsubsection{Implementation (Final System)}

In this stage the prototype will be executed if the prototype is accepted by user. The accepted prototyped will became the fundamental of final system and the user interface of final system will be enhancing. After the final is developed, final testing will have performed. If there no any problem the final system will be deploy and implement in real operating environment. Last but not list, the whole process of development must be documented so it will easier to maintain the system in future.

\section{ANALYSIS}

\subsection{Introduction}

For analysis Projector Tracking System Using RFID the information gathering has been depict from the chapter methodology and the analysis will direct and demonstrate the result based on the data collection. The analysis will use to compare with the requirement and the data was collect with interview section two weeks before assemble the information and its gather from FCVAC Admin and Lecturer's. The analysis section also will contain user requirement, system requirement and functional and its will reflect how the system works.

\subsection{User requirement}

The main target users for this system would be Admin staff who is faculty administrator. The target users were identified based on the interview section was conducted in earlier. All the flow of the tracking projector is collected and stated as the user requirements.

\subsubsection{Survey analysis}

This project is conducting an interview session and a couple of issues that relate by user fulfilment and services can be analyzed. The meeting session was direct at the Admin Office and Lecturer's office and the question of interview was printed and provide for the Lecturer's and Admin Staff as references.

\section{DESIGN}

\subsection{Introduction}

This chapter portrays the assignments of how the system will be organized and constructed in order to control in the physical development of system. It gives how the system would be. The plan of the Projector Tracking System Using RFID depends on the user requirements accumulated and additionally from the study's which had been conducted. A few strategies are utilized to demonstrate the plan of the proposed system, including architecture diagram, system design (class diagram, use case diagram, sequence diagram, activity diagram) and database design (ERD diagram for the database design and data dictionary).

\subsection{System architecture}

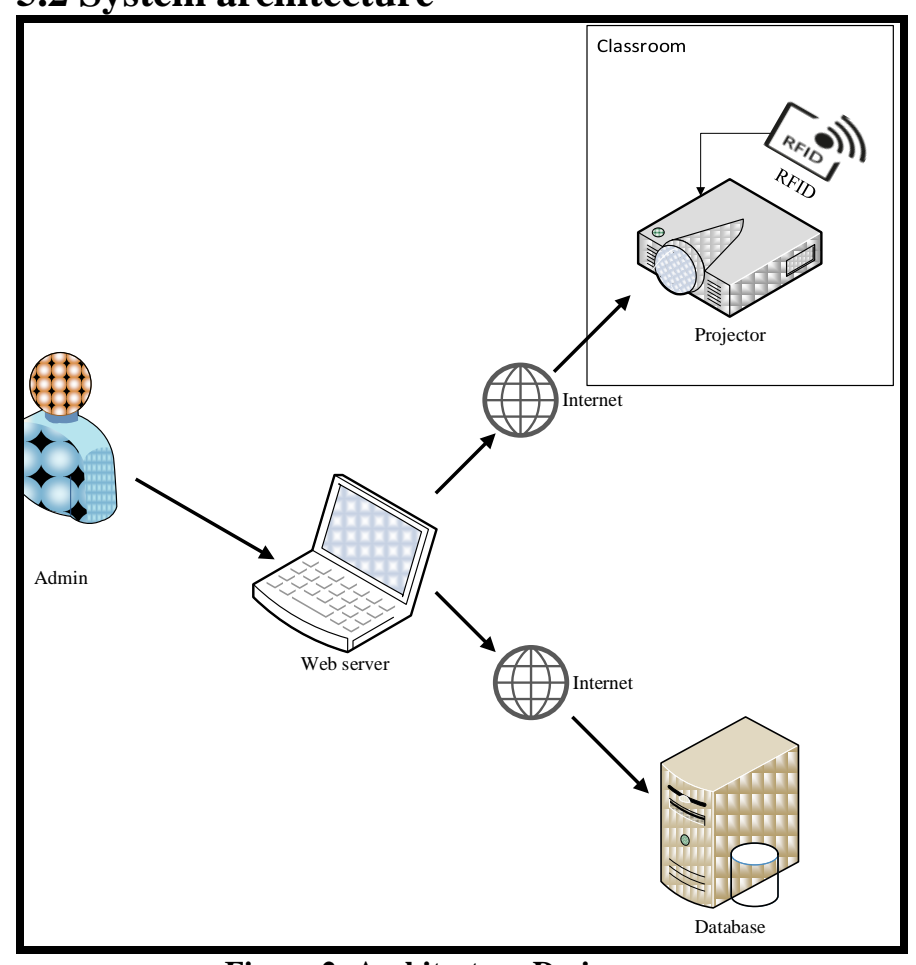

Figure 2: Architecture Design

Figure 2 shows the flow of architecture design of the system. The architecture the elements involved in proposed system. Users need personal computer (PC) or laptop, projector and RFID to use the proposed system. Internet connection needed to access the website.

\section{CONCLUSION}

In conclusion, author have learned a lot of lessons and gained a lot of knowledge regarding a system. Projector tracking system using RFID has given the author an experience of developing a system based on the requirement. Finally, author has fulfilled the objectives. Author able to learn more deep about the coding and how to implement while developing the system. Moreover, 
projector tracking system using RFID could help the admin staff to manage the projector details and save time.

\section{REFERENCES}

[1] Angerer, C., \& Langwieser, R. (2009). Flexible evaluation of RFID system parameters using rapid prototyping. In 2009 IEEE International Conference on RFID, RFID 2009 (pp. 42-47). https://doi.org/10.1109/RFID.2009.4911188

[2] Ltd., B. T. P. (2017). Our Solutions Our Services Request for a Quote, 2017. Retrieved from http://www.bizlogics.co.in/

[3] Group, G. (2017). RFID Company With Over 20 Years of Innovation Our RFID Hardware RFID Peripherals \& Antennas Our RFID Software Our RFID Systems Ask an Expert, 1-4. Retrieved from http://gaorfid.com/

[4] Sysaid Software (n.d.) Retrieve October 4, 2016, from https://www.sysaid.com/

[5] Technology, C. (2008). Securing Assets with RFID.

[6] Yilmaz, A., Javed, O., \& Shah, M. (2006). Object tracking: A survey. ACM Comput. Surv., 38(4), 13. https://doi.org/http://doi.acm.org/10.1145/1177352.117735 5

[7] Birkfellner, W., Hummel, J., Wilson, E., \& Cleary, K. (2008). Tracking devices. In Image-Guided Interventions: Technology and Applications (pp. 23-44). https://doi.org/10.1007/978-0-387-73858-1_2

[8] Language, P., Likes, F., Software, W. I., Software, E. O., Life, S. D., Model, W., Time, R. (2017). 07- Advantages and Disadvantages of Prototype Model | prototype mod
Advantages and Disadvantages of Prototyping Advantages of Prototyping: Disadvantages of Prototyping: VIDEO Tutorial, $1-2 . \quad$ Retrieved from http://www.tutorialsspace.com

[9] V H. (2002). Efficient Object Identification with Passive RFID Tags. Pervasive Computing, 98--113. https://doi.org/10.1007/3-540-45866-2_9

[10] (Al, Ph, Nayar, \& Ph, 2015)Al, M. K., Ph, D., Nayar, M. M. Al, \& Ph, D. (2015). Designing Smart University using RFID and WSN, 112(15), 34-39.

[11] (Agarwal \& Dive, 2014)Agarwal, K. S., \& Dive, K. (2014). RFID Based Intelligent Bus Management and Monitoring System, 3(7), 6-13.

[12] (Karthika, Harriet, Priya, \& Pandian, 2015)Karthika, P., Harriet, J., Priya, R., \& Pandian, A. R. (2015). Indoor Location Tracking System Using RFID Technology. International Journal of Engineering Research and Reviews ISSN, 3(1), 2348-697.

[13] (Hui, Chan, \& Fung, 2014)Hui, F. C. P., Chan, H. C. B., \& Fung, S. H. (2014). RFID - based Location Tracking System Using a Peer - to - Peer Network Architecture. Imecs 2014, I, 1-5.

[14] (Boži，2013)Boži， M. (2013). RFID technology based object tracking system.

[15] (Prinsloo \& Malekian, 2016)Prinsloo, J., \& Malekian, R. (2016). Accurate vehicle location system using RFID, an internet of things approach. Sensors (Switzerland), 16(6). https://doi.org/10.3390/s16060825 